Article

\title{
Performance Investigation and Optimization of a Novel Hybrid Saturated-Core Fault-Current Limiter Considering the Leakage Effect
}

\author{
Liangliang Wei ${ }^{1,2}$, Baichao Chen ${ }^{1}$, Yushun Liu ${ }^{3} \mathbb{D}^{\mathbb{D}}$, Cuihua Tian ${ }^{1}$, Jiaxin Yuan ${ }^{1, *} \mathbb{D}^{\mathbb{D}}$, Yuxin Bu ${ }^{4}$ \\ and Tianan $\mathrm{Zhu}^{5}$ \\ 1 School of Electrical Engineering, Wuhan University, No.299, Bayi Street, Wuchang District, Wuhan 430072, \\ China; wl190623@163.com (L.W.); whgycbc@163.com (B.C.); tianch@whu.edu.cn (C.T.) \\ 2 Department of Electrical Engineering, Graduate School of Engineering, Kyoto University, \\ Yoshida-honmachi, Sakyo-ku, Kyoto 606-8501, Japan \\ 3 Anhui Grid Co., Anhui Electric Power Research Institute, No.73, Jinzhai Road, Hefei 230022, China; \\ silencelys@163.com \\ 4 State Grid Taiyuan Power Supply Company, No.89, Binzhou North Road, Taiyuan 030012, China; \\ byx406123472@126.com \\ 5 State Grid Yichang Power Supply Company, No.42, Chengdong road, Yichang 443000, China; \\ anan2618579@gmail.com \\ * Correspondence: yjx98571@163.com; Tel.: +86-186-2775-5068
}

Received: 20 November 2017; Accepted: 20 December 2017; Published: 1 January 2018

\begin{abstract}
To reduce the requirement of DC-biasing capacity and improve the biasing ability of a permanent magnet (PM), a novel hybrid saturated-core fault-current limiter (HSCFCL) is proposed in this paper. Compared with traditional saturated-core fault-current limiter (SCFCL), the HSCFCL has the advantages of small size, low DC-biasing capacity, a high biasing ability of the PM and excellent limiting performance. Firstly, the principle and the magnetic circuit model of the HSCFCL are introduced. Then, the improvement of DC-biasing capacity with a PM is analyzed. In addition, the influence of the leakage-flux effect on the biasing ability of the PM is presented in detail, and a small-section optimal structure is proposed to improve the biasing ability of the PM. Finally, to validate the principle and performance of the HSCFCL, various electromagnetic simulations, optimization studies and experiments are carried out. The simulation and experimental results demonstrate the effectiveness of the proposed method.
\end{abstract}

Keywords: saturated-core fault-current limiter; DC biasing ability; permanent magnet; leakage flux effect; small section

\section{Introduction}

Since renewable energy, energy demand and the scale of power grids continue to grow, excessive short-circuit current has been a serious problem for power systems [1-4]. Traditional current-limiting measures such as an air-core reactor and network splitting have some disadvantages [5]. Fault-current limiter devices (FCL) are becoming a promising technology to limit fault current. There are several types of FCLs [6-8]. The saturated-core fault-current limiter (SCFCL) has attracted worldwide attention from researchers and companies and has the advantages of fault self-detection, fast action and a high withstanding voltage [9-11].

The SCFCL utilizes the non-linear permeability of ferromagnetic materials to provide a low impedance under normal conditions and a large limiting impedance under fault conditions in order to limit the fault current [12]. Under normal conditions, the DC magnetic-motive-force (MMF) produced by DC coils drives the cores into saturation, and the impedance of SCFCL is low. During a fault event, 
the large fault current drops the cores out of saturation, resulting in a large increase of impedance for limiting the fault current. However, there are two major problems limiting the development of traditional SCFCLs.

The first problem is the large DC-biasing capacity of DC coils under normal conditions. Superconducting coils and permanent magnets (PMs) can be used to solve the problem. However, the superconducting materials and cooling system are expensive and energy consuming [13-15]. In addition, the biasing capacity of PMs is inadequate [16]. To reduce the requirement of the DC-biasing capacity of traditional SCFCLs, a hybrid DC coil/PM design in an open-core SCFCL is discussed [17]. However, the reduction of the fault-clipping performance needs to be improved. Modelled on an open-core type, a hybrid 4-limb close-core SCFCL based on PMs is discussed [18]. But the structure is complex and large in size. Moreover, there is a lack of detail in comparative studies about the impact of PMs on DC-biasing capacity and the fault-clipping performance of PMs.

Additionally, due to the PM and the deep saturation of cores, the leakage-flux effect is obvious, and has a significant influence on the performance of the SCFCL and the biasing ability of the PM. An analytical model of a PM fault-current limiter device (PMFCL) considering the leakage-flux effect is established in [19]. A small-section structure of the PMFCL is proposed to improve the biasing ability of the PM in [20]. However, there has been a lack of attention to the biasing ability of the PM that considers the leakage effect and the optimization of a small-section structure in a hybrid DC coil/PM structure.

The second problem for existing SCFCLs is insufficient limiting performance. Due to the coupling effect between the AC and DC windings, even though the cores are driven out of saturation, the limiting impedance of the SCFCL is still not large, resulting in insufficient limiting performance [21]. A bridge-type SCFCL with limiting inductor is proposed to improve limiting performance [22].

This paper proposed a novel hybrid saturated-core fault-current limiter (HSCFCL), which has the advantages of small size, low DC-biasing capacity, a high biasing ability of the PM, and excellent limiting performance. The hybrid DC coil/PM structure is proposed to reduce the DC-biasing capacity. A small-section optimal structure is proposed to improve the biasing ability of the PM. A limiting inductor in series with the DC-biasing circuit is proposed to improve the limiting performance. Firstly, the fundamental principle and the magnetic circuit model of HSFCCL are introduced in Section 2. Then, Section 3 presents the biasing ability analysis of the PM considering the leakage effect in detail. Finally, various simulations, optimization studies and experiments are performed in Section 4. The simulation and experimental results verify the effectiveness of the proposed structure. In Section 5, conclusions are summarized.

\section{Fundamental Principle and Magnetic Circuit Model of the HSCFCL}

To describe the principle conveniently, the main symbols and definitions in this paper are firstly given, as shown in Table 1.

Table 1. Symbols and definitions.

\begin{tabular}{cccc}
\hline Symbol & Definition & Symbol & Definition \\
\hline$\phi_{m 1}$ & Flux of cores I & $X_{n o m}$ & Normal impedance of HSCFCL \\
$\phi_{m 2}$ & Flux in cores II & $Z_{F C L}$ & Inserted impedance of HSCFCL \\
$\phi_{m 3}$ & Flux in cores II & $L_{0}$ & Limiting inductance \\
$r_{e 1}$ & Reluctance of core I & $M M F_{d}$ & DC MMF produced by DC coils \\
$r_{e 2}$ & Reluctance of core II & $M M F_{P M}$ & DC MMF produced by PMs \\
$r_{u}$ & Reluctance of core III & $\Delta M M F_{P M}$ & Improvement of DC MMF \\
$\mu_{u}$ & Unsaturated permeability of iron core & $I_{d}$ & DC current \\
$\mu_{s r}$ & Saturated permeability of iron core & $S_{e}$ & Cross-sectional area of core I \\
$L_{u}$ & Unsaturated inductance of a winding & $l_{e}$ & Length of core I \\
$L_{s}$ & Saturated inductance of a winding & $S_{b}$ & Cross-sectional area of small section \\
$N$ & Number of winding turns & $l_{b}$ & Length of small section \\
\hline
\end{tabular}




\subsection{Basic Configuration of the HSCFCL}

Figure 1 shows a basic configuration of the HSCFCL, which has three cores, AC coils, DC coils, PMs, a limiting inductor and a biasing DC source. The hybrid biasing structure of the DC coils and PMs is used to drop the cores into saturation, resulting in a reduction of the DC-biasing capacity. The MMF produced by the PMs and DC coils are in same direction. In order to limit both the positive and negative half cycles of a fault-current effectively, the DC MMFs of cores I and II are in opposite directions. The limiting inductor $L_{0}$ which is in series with the biasing DC source is used to enhance the limiting performance. The small-section parts in cores I and II are used to improve the biasing ability of the PMs. The cross-sectional area of the small-section part is reduced to $S_{b}$ (which is smaller than that of the main core $S_{e}$ ); the length of the small-section part is $l_{b}$.

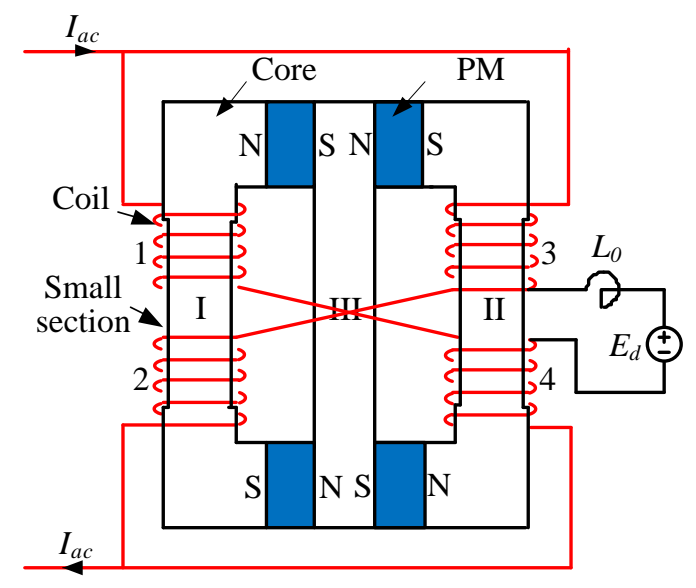

Figure 1. Basic configuration of the hybrid saturated-core fault-current limiter (HSCFCL).

\subsection{Magnetic Circuit Modeling}

According to the configuration of the HSCFCL, magnetic flux loops of cores and PMs have been established, as shown in Figure 2a. The DC flux set up by the DC coils $\phi_{d c}$ and the DC flux set up by the PMs $\phi_{P M}$ mainly flow through cores I and II, and the AC flux mainly flows through core III. Figure $2 b$ shows an equivalent magnetic circuit model of the HSCFCL. To simplify the analysis, assume that the magnetization curve of the iron core is a double-line model. The saturated permeability of the iron core is equal to that of air $\mu_{0}$, and the unsaturated permeability of the iron core is $\mu_{u} . \phi_{m 1}, \phi_{m 2}$ and $\phi_{m 3}$ represent the fluxes in cores I, II and III, respectively. $r_{e 1}, r_{e 2}$ and $r_{u}$ represent the reluctances of core I, II and III, respectively.

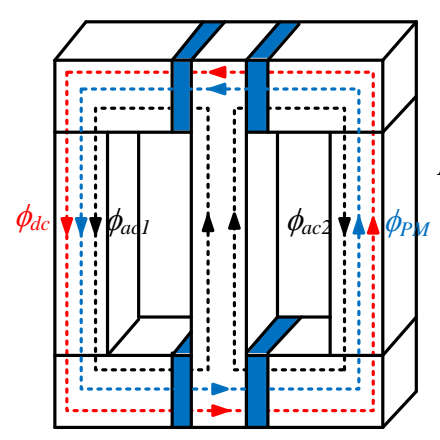

(a) Magnetic flux loops

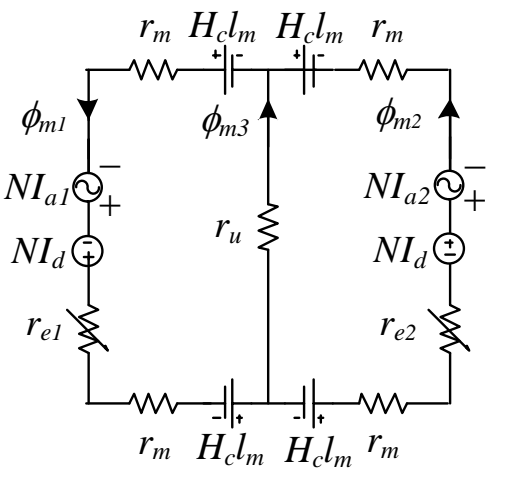

(b) Magnetic circuit model

Figure 2. Equivalent magnetic circuit model of the HSCFCL. (a) Magnetic flux loops; (b) magnetic circuit model. 
Assume that the AC is in the positive half cycle. Using the loop current method:

$$
\left\{\begin{array}{l}
-2 H_{c} l_{m}+2 r_{m} \phi_{m 1}+H_{e 1} l_{e}-N I_{a c}-N I_{d}+r_{u 3}\left(\phi_{m 1}-\phi_{m 2}\right)=0 \\
-2 H_{c} l_{m}+2 r_{m} \phi_{m 2}-H_{e 2} l_{e}+N I_{a c}-N I_{d}+r_{u 3}\left(\phi_{m 2}-\phi_{m 1}\right)=0 \\
\phi_{m 3}=\phi_{m 1}-\phi_{m 2}
\end{array}\right.
$$

where $H_{e 1}$ is the magnetic field strength of core I; $H_{e 2}$ is the magnetic field strength of core II; $l_{e}$ is the length of the magnetic path of core I or core II; $N$ is the number of winding turns; $I_{a c}$ is the alternating current through the HSCFCL; and $I_{d}$ is the DC biasing current.

Under normal conditions, cores I and II are dropped into deep saturation by DC MMFs produced by the DC coils and PM. $I_{a c 1}=I_{a c 2}=I_{a c}, r_{e 1}=r_{e 2}=r_{s}=l_{e} / A_{z} \mu_{s r}, H_{e 1}=H_{e 2}=H_{e}$. Hence, the fluxes in core I, II, and III can be calculated by solving (1):

$$
\left\{\begin{array}{l}
\phi_{m 1}=\frac{2 H_{c} l_{m}+N I_{d}}{2 r_{m}}+\frac{N I_{a c}-H_{e} l_{e}}{2\left(r_{m}+r_{u 3}\right)} \\
\phi_{m 2}=\frac{2 H_{c} l_{m}+N I_{d}}{2 r_{m}}-\frac{N I_{a c}-H_{e} l_{e}}{2\left(r_{m}+r_{u 3}\right)} \\
\phi_{m 3}=\phi_{m 1}-\phi_{m 2}=\frac{N I_{a c}-H_{e} l_{e}}{\left(r_{m}+r_{u 3}\right)}
\end{array}\right.
$$

It can be seen that the DC MMF produced by the PMs and DC coils mainly flow through cores I and II. Core III mainly transports the AC MMF, as shown in Figure 3a. Moreover, although the DC MMF is enhanced with the PMs, the reluctance of the DC magnetic loop also increases. Hence, the improvement of DC-biasing capacity by PMs needs to be further studied.

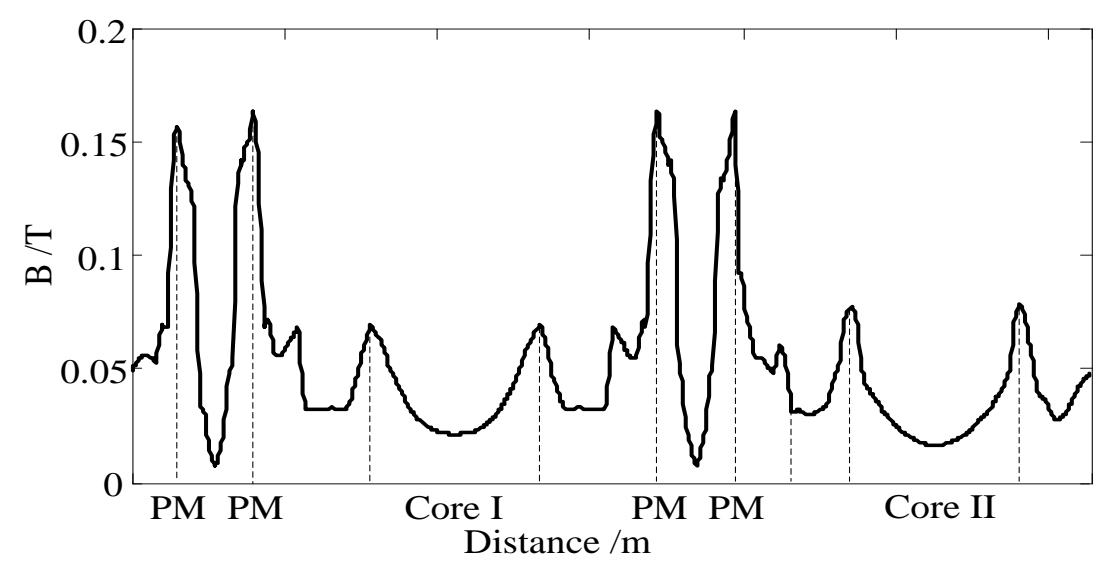

Figure 3. Leakage flux density distribution of the air region near the HSCFCL without the small section.

Since $\phi_{m 1}, \phi_{m 2}, H_{e}$ and $I_{a c}$ are functions of time $t$, the saturated inductance of a winding can be expressed as:

$$
L_{s}=N \frac{d \phi_{m 1}}{d t} / \frac{d\left(I_{a c} / 2\right)}{d t}=\frac{2 N^{2}}{2\left(r_{m}+r_{u 3}\right)+r_{s}}
$$

The unsaturated inductance of a winding can also be expressed as:

$$
L_{u}==\frac{2 N^{2}}{2\left(r_{m}+r_{u 3}\right)+r_{u}}
$$

Hence, the normal impedance of HSCFCL is:

$$
X_{n o m}=\omega \cdot L_{s}=\frac{2 \cdot \omega \cdot N^{2}}{2\left(r_{m}+r_{u 3}\right)+r_{s}}
$$


Since the permeability of the cores in saturation and the PM are approximately equal to that of air, the normal impedance of the HSCFCL under normal conditions is very low.

Under fault conditions, assume that the fault current is in the positive half cycle. Then, core I is saturated, and core II is unsaturated. The fault current flows through the windings of core I and the limiting inductor $L_{0}$. Hence, the inserted impedance of the HSCFCL under fault conditions $Z_{F C L}$ can be expressed as:

$$
Z_{F C L}=\omega *\left(2 L_{s}+L_{0}\right)=\omega *\left(\frac{4 N^{2}}{2\left(r_{m}+r_{u 3}\right)+r_{s}}+L_{0}\right)
$$

\subsection{Improvement of DC-Biasing Capacity with PMs}

Compared with traditional SCFCLs with DC coils, the hybrid structure of the DC coils and PMs can reduce the DC current of the DC coil, resulting in a reduction of the DC-biasing capacity and losses.

To drive cores into saturation under normal conditions, using the loop current method:

$$
N I_{d}+2 H_{c} l_{m}-2 r_{m} \phi_{s}-H_{s} l_{e}=N I_{c m}
$$

where $I_{c m}$ is the critical normal current.

Assume the DC MMF produced by the DC coils $M M F_{d}=N I_{d}$, the DC MMF produced by PMs $M M F_{P M}=2 H_{c} l_{m}$. Since $H_{c}=B_{r} / \mu_{m}, r_{m}=l_{m} /\left(\mu_{m} S_{m}\right)$, the DC MMF produced by the DC coils can be expressed as:

$$
M M F_{d}=N I_{c p}+H_{s} l_{e}+M M F_{P M}\left(1-\frac{B_{s} S_{e}}{B_{r} S_{m}}\right)
$$

Without PMs, the DC MMF of the traditional SCFCL which is needed to drive the cores into saturation is:

$$
M M F_{d}^{\prime}=N I_{c p}+H_{s} l_{e}
$$

Thus, the improvement of the DC MMF with PMs can be calculated as:

$$
\Delta M M F_{d}=M M F_{d}^{\prime}-M M F_{d}=M M F_{P M}\left(1-\frac{B_{S} S_{e}}{B_{r} S_{m}}\right)
$$

It can be seen that, if $B_{s} S_{e} /\left(B_{r} S_{m}\right)<1$, the improvement is positive. Hence, the HSCFCL can reduce the DC-biasing capacity when appropriate parameters of cores and PM materials are designed. The materials of the core and PM in this paper are Grade Silicon steel $30 \mathrm{Q} 140\left(H_{s}=10 \mathrm{kA} / \mathrm{m}, B_{s}=2.0 \mathrm{~T}\right.$ and NdFeB N50 $\left(H_{c}=836 \mathrm{kA} / \mathrm{m}, B_{r}=1.45 \mathrm{~T}\right)$, respectively. Thus, the cross-sectional area of the PM and cores should be satisfied as:

$$
\frac{S_{m}}{S_{e}}>\frac{B_{s}}{B_{r}}=1.379
$$

In addition, to ensure excellent limiting performance under fault conditions, the limiting inductance $L_{0}$ should be less than $k L_{u}, k$ is $0.01 \sim 0.1$. Hence:

$$
\frac{X_{F C L}-2 X_{n o m}}{\omega} \leq k L_{u}=\frac{k N^{2}}{2 r_{m}+2 r_{u}}
$$

Since $r_{u}$ is much less than $r_{m}, r_{u}$ can be ignored. Hence, to ensure the limiting performance, $M M F_{P M}$ has a maximum value:

$$
M M F_{P M} \leq \frac{\omega k N^{2} B_{r} S_{m}}{20\left(X_{F C L}-X_{n o m}\right)}=M M F_{P \max }
$$


By increasing the $M M F_{P M}$, the improvement of the DC MMF will increase. When $M M F_{P M}=M M F_{P \max }$, the improvement of the DC MMF is maximum, and the length of PM can be calculated as:

$$
l_{m}=\frac{\omega k N^{2} B_{r} S_{m}}{2 H_{c}\left(X_{F C L}-X_{n o m}\right)}
$$

\section{Biasing Ability Analysis of the PM Considering the Leakage Effect}

Under normal conditions, cores I and II are driven into deep saturation. The leakage flux will make the flux density distribution of the cores uneven. Moreover, due to the PMs, the leakage effect of the HSCFCL is more obvious and should be considered. Figure 3 shows the leakage-flux density distribution of the air region near the HSCFCL without small sections.

It can be seen that the leakage effect of the HSCFCL is significant. The leakage-flux density near the PM is largest with about $0.15 \mathrm{~T}$. In addition, the leakage-flux density near cores I and II is smaller, but the leakage-flux density distribution is uneven, resulting in uneven flux density distribution of the cores. The flux density in the central part of the cores is smaller than that in the terminal part of the cores close to the PMs.

The significant leakage effect will severely weaken the biasing ability of the PMs and the improvement of DC-biasing capacity. Moreover, the uneven flux density distribution of cores I and II will reduce the saturation degree of the cores, leading to a reduction in the biasing ability of the PMs and an improvement of DC-biasing capacity. Hence, the influence on the biasing ability of the PMs considering the leakage effect should be analyzed and improved.

To simplify the analysis, the HSCFCL is equivalent to a 2D model, ignoring the edge effect. According to the principle of magnetic field division, the air region above the HSCFCL is divided in six types of cylindrical flux tubes with different cross-sectional areas, which are referred to as the arch type $A_{1}$, similar circular type $A_{2}$, semi-lunar type $A_{3}$, semi-circular type $A_{4}$, semi-lunar type $A_{5}$, and semi-circular type $A_{6}$, as shown in Figure 4.

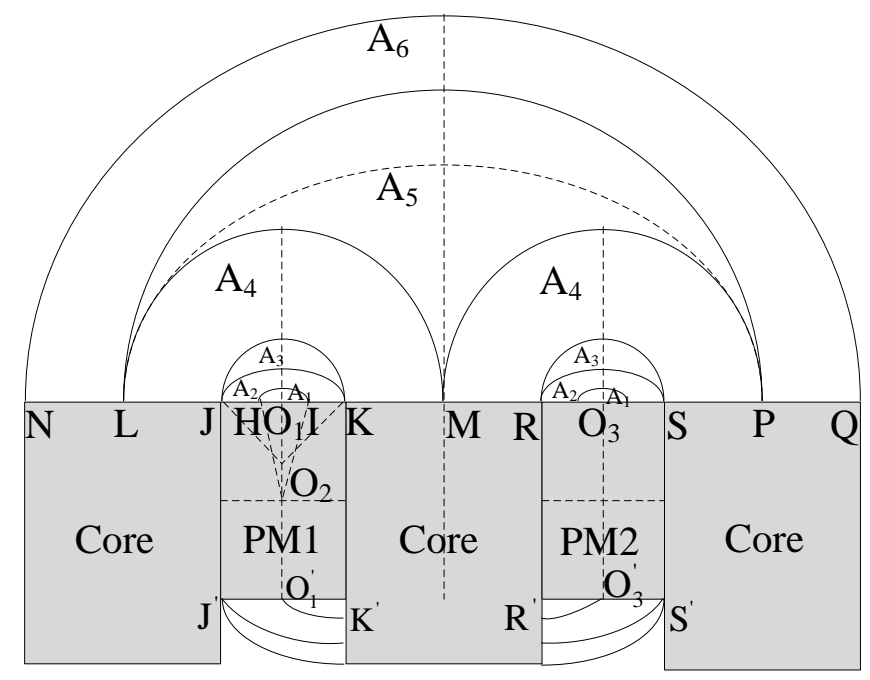

(a)

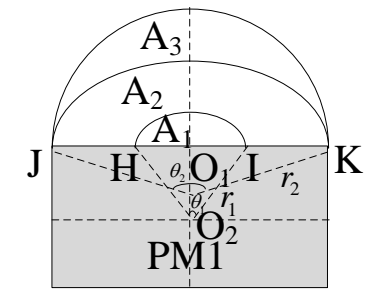

(b)

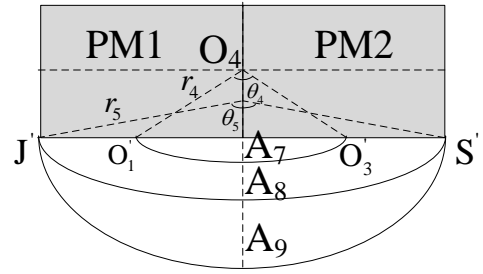

(c)

Figure 4. Magnetic field division of the air region of the HSCFCL. (a) Magnetic field division of whole air region; (b)Magnetic field division of air region near PM1; and (c) Magnetic field division of air region below PMs. 


\subsection{Arch-Type Flux Tube $A_{1}$}

The arch-type flux tube represents the leakage flux emitted from line $\mathrm{HO}_{1}$ of the $\mathrm{PM}$ to line $\mathrm{IO}_{1}$. According to the principle of magnetic-field division, the permeance of the arch-type flux tube $\mathrm{A}_{1}$ can be calculated as:

$$
G_{A 1}=\frac{\mu_{0} W_{d} \theta_{1}}{12}
$$

where $W_{d}$ is the width of PM; and $\theta_{1}$ is the angle of arc HI.

\subsection{Similar Circular-Type Flux Tube $A_{2}$}

The similar circular type flux tube $\mathrm{A}_{2}$ represents the leakage flux emitted from line JH of the PM to line IK. According to the infinitesimal method, the permeance of the similar circular type flux tube $\mathrm{A}_{2}$ can be calculated as:

$$
G_{A 2}=\int_{r_{1}}^{r_{2}} \frac{\mu_{0} W_{d}}{r \pi} d r
$$

where $r_{1}$ and $r_{2}$ are the radius of arcs $\mathrm{HI}$ and JK, respectively.

\subsection{Semi-Lunar Type Flux Tube $A_{3}$}

The semi-lunar type flux tube $\mathrm{A}_{3}$ represents the leakage flux emitted from point $\mathrm{J}$ to point $\mathrm{K}$. The permeance of the semi-lunar type flux tube $\mathrm{A}_{3}$ can be calculated as:

$$
G_{A 3}=\frac{\mu_{0} W_{d}\left(\pi-\theta_{2}\right)}{12}
$$

where $\theta_{2}$ is the angle of arc JK.

\subsection{Semi-Circular Type Flux Tube $A_{4}$}

The semi-circular type flux tube $\mathrm{A}_{4}$ represents the leakage flux emitted from side $\mathrm{LJ}$ of the iron core to side KM. Point M is the center of core III. The permeance of the semi-circular type flux tube $\mathrm{A}_{4}$ can be calculated as:

$$
G_{A 4}=\frac{\mu_{0} W_{d}}{\pi} \ln \frac{\mathrm{LM}}{\mathrm{JP}}
$$

where LM and JP are the length of lines LM and JP.

\subsection{Semi-Lunar Type Flux Tube $A_{5}$}

The semi-lunar type flux tube $A_{5}$ represents the leakage flux emitted from point $L$ of PM1 to point $\mathrm{P}$ of PM2. The permeance of the semi-lunar type flux tube $\mathrm{A}_{5}$ can be calculated as:

$$
G_{A 5}=\frac{\mu_{0} W_{d}\left(\pi-\theta_{3}\right)}{12}
$$

where $\theta_{3}$ is the angle of arc LP.

\subsection{Semi-Circular Type Flux Tube $A_{6}$}

The semi-circular type flux tube $A_{6}$ represents the leakage flux emitted from surface side NL of the iron core to surface side $\mathrm{PQ}$. The permeance of the semi-circular type flux tube $\mathrm{A}_{6}$ can be calculated as:

$$
G_{A 6}=\frac{\mu_{0} W_{d}}{\pi} \ln \frac{\mathrm{NQ}}{\mathrm{LP}}
$$

where NQ and LP are the length of lines NQ and LP. 
In addition, the air region below the PMs can be divided into three magnetic tubes: $A_{7}, A_{8}$ and $\mathrm{A}_{9}$, as shown in Figure $4 \mathrm{c}$. The permeance of the three magnetic tubes can be expressed as:

$$
\begin{gathered}
G_{A 7}=\frac{\mu_{0} W_{d} \theta_{4}}{12} \\
G_{A 8}=\int_{r_{4}}^{r_{5}} \frac{\mu_{0} W_{d}}{r \pi} d r \\
G_{A 9}=\frac{\mu_{0} W_{d}\left(\pi-\theta_{5}\right)}{12}
\end{gathered}
$$

where $\theta_{4}$ and $\theta_{5}$ are the angles of $\operatorname{arcs} \mathrm{O}_{1}{ }^{\prime} \mathrm{O}_{3}{ }^{\prime}$ and $\mathrm{J}^{\prime} \mathrm{O}^{\prime}$, respectively; and $r_{4}$ and $r_{5}$ are the radius of arcs $\mathrm{O}_{1}{ }^{\prime} \mathrm{O}_{3}{ }^{\prime}$ and $\mathrm{J}^{\prime} \mathrm{O}^{\prime}$, respectively.

It can be seen that the permeances of tube $A_{1}, A_{2}, A_{3}$ and $A_{4}$ are parallel, the permeances of tube $A_{5}$ and $A_{6}$ are parallel, and the permeances of tube $A_{7}, A_{8}$ and $A_{9}$ are parallel. Assuming $G_{1}=G_{A 1}+G_{A 2}+G_{A 3}+G_{A 4}, G_{2}=G_{A 5}+G_{A 6}, G_{3}=G_{A 7}+G_{A 8}+G_{A 9}, G_{m}$ is the permeance of PM. Hence, the equivalent permeance model of the PMs considering the leakage effect is shown in Figure 5.

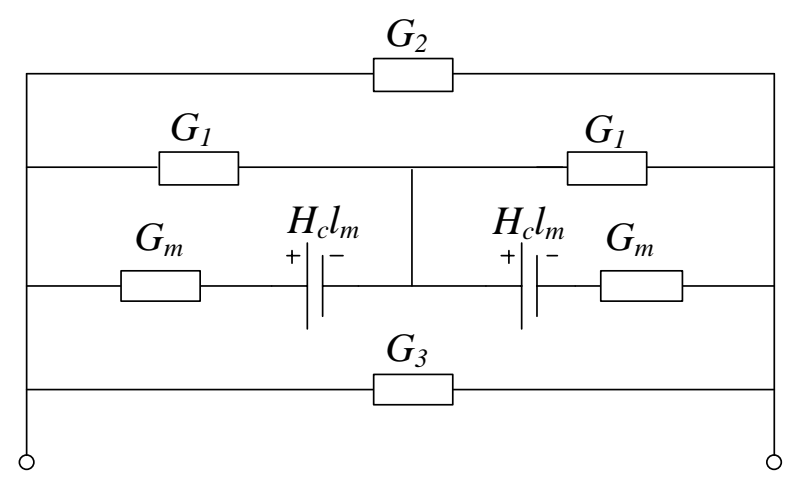

Figure 5. Equivalent permeance model of permanent magnets (PMs) considering the leakage effect.

According to Thevenin equivalent principle, Thevenin equivalent MMF and reluctance of PM can be expressed as:

$$
\begin{gathered}
F_{m}^{\prime}=H_{c} l_{m} \cdot \frac{G_{m}}{G_{m}+G_{1}+2 G_{2}+2 G_{3}} \\
R_{m}^{\prime}=\frac{1}{G_{m}+G_{1}+2 G_{2}+2 G_{3}}
\end{gathered}
$$

Hence, due the leakage effect, the equivalent MMF of PM will decrease, resulting in a reduction of the biasing ability of the PM. The length of the PM that is needed should be longer than that of Equation (14) when considering the leakage-flux effect.

Hence, to improve the biasing ability of the PM and reduce the length of the PMs, a small section part is proposed. Due to the cross-sectional area being smaller than that of main core, this can make the flux-density distribution of the cores more even. The cross-sectional area and length of the small-section part should be studied.

\section{Results}

To validate the performance and improvement of the DC-biasing capacity of a HSCFCL in a power grid, a single-phase $10 \mathrm{kV} / 1 \mathrm{kA}$ HSCFCL finite element analysis (FEA) model was established. Various FEA simulations using the non-linear field-circuit coupling method and optimization studies of the HSCFCL were performed. In the simulation setup, the material characteristics of the cores were the actual non-linear model. An ideal voltage source was used as the power source, and an ideal 
switch was used as the circuit breaker. The parameters of the HSCFCL model are presented in Table 2. To validate the influence of the PMs, the SCFCL without PMs whose other parameters are the same was performed for comparison. The parameters of the PM and the small-section part have been optimized.

Table 2. Parameters of the HSCFCL model.

\begin{tabular}{cc}
\hline Parameter & Value \\
\hline Cross-sectional area of cores I and II $/ \mathrm{m}^{2}$ & 0.2025 \\
Cross-sectional area of cores III $/ \mathrm{m}^{2}$ & 0.261 \\
Cross-sectional area of small section $/ \mathrm{m}^{2}$ & 0.189 \\
Length of cores $l_{e} / \mathrm{m}$ & 2.2 \\
Length of small section $l_{b} / \mathrm{m}$ & 1.8 \\
Cross-sectional area of $\mathrm{PM} / \mathrm{m}^{2}$ & 0.405 \\
Length of PM $/ \mathrm{m}$ & 0.15 \\
Number of winding turns $N$ & 37 \\
Inductance of limiting inductor $L_{0} / \mathrm{mH}$ & 1.93 \\
Steel cores & $H_{s}=10 \mathrm{kA} / \mathrm{m}, B_{s}=2.0 \mathrm{~T}$ \\
Permanent magnets & $H_{c}=836 \mathrm{kA} / \mathrm{m}, B_{r}=1.45 \mathrm{~T}$ \\
\hline
\end{tabular}

\subsection{FEA Simulation and Optimization}

Figure 6 shows the DC current and normal voltage of the HSCFCL and SCFCL without PMs under normal conditions. It can be seen that, compared with SCFCL without PMs, the DC current can be reduced from $2.1 \mathrm{kA}$ to $1.0 \mathrm{kA}$. Hence, the HSCFCL has a $52.3 \%$ reduction in DC-biasing capacity. Additionally, because of the reluctance of the PMs, the normal voltage can also be reduced from $179.0 \mathrm{~V}$ to $156.0 \mathrm{~V}$ with a $12.8 \%$ reduction.

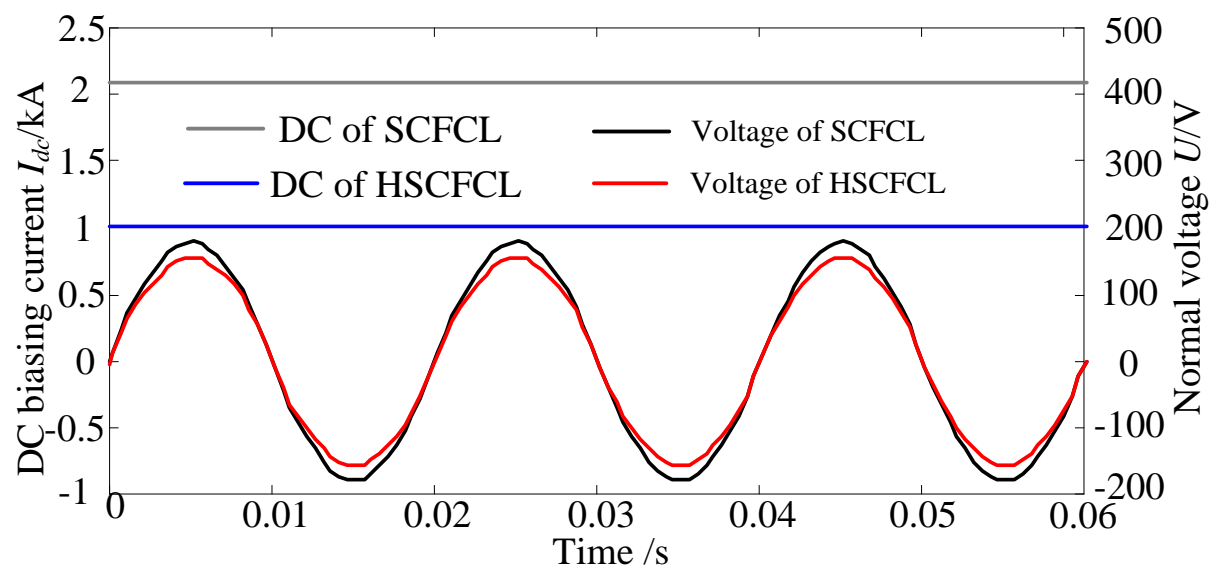

Figure 6. DC current and normal voltage of the HSCFCL and SCFCL without PMs under normal conditions.

The current of the HSCFCL is shown in Figure 7. It shows that the fault current is limited from $30 \mathrm{kA}$ to $11.0 \mathrm{kA}$ with the HSCFCL. A HSCFCL with $L_{0}=0 \mathrm{mH}$ represents the traditional hybrid FCL. It can be seen that, compared with traditional hybrid FCLs, the proposed HSCFCL has better limiting performance. In addition, compared with the SCFCL without PMs, the limiting performance is weakened by $10 \%$. However, the HSCFCL also has good limiting performance, meeting the limiting requirement of the power grid. 


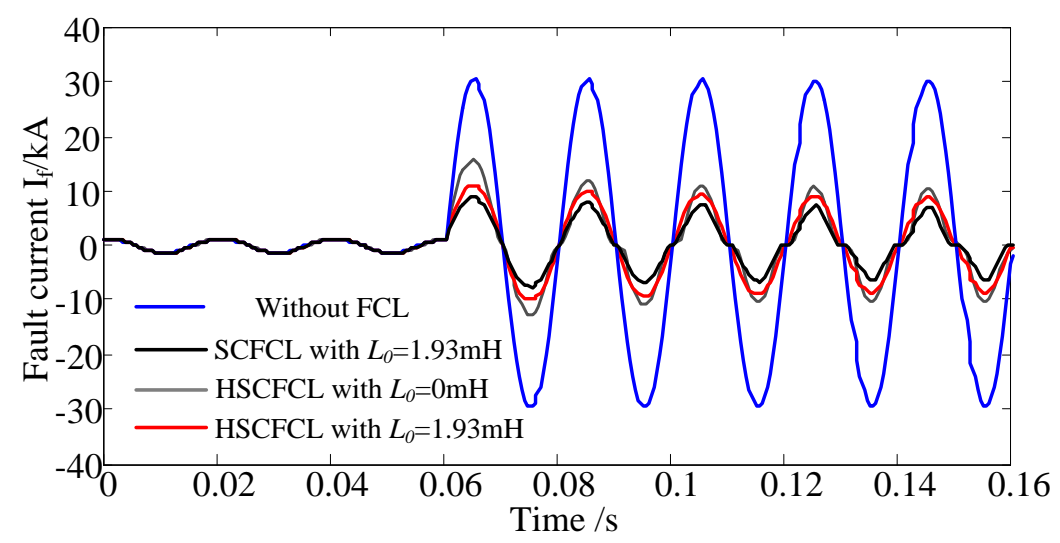

Figure 7. Comparative results of current.

Figure 8 shows the currents of the coil on core II under different limiting inductances. It can be seen that the limiting performance of the HSCFCL can be improved when the limiting inductance increases. However, due to the reluctance of the PMs, the unsaturated inductance of the winding is not so large compared with the limiting inductance. Hence, with an increase in the limiting inductance, the current of the coil on the unsaturated core will also increase, resulting in a weakening of limiting performance. Compared with the SCFCL with the same limiting inductance $L_{0}=1.93 \mathrm{mH}$, the current of the HSCFCL coil is larger. Hence, Figures 7 and 8 demonstrate that the reluctance of the PMs will have some impact on the limiting performance of the HSCFCL.

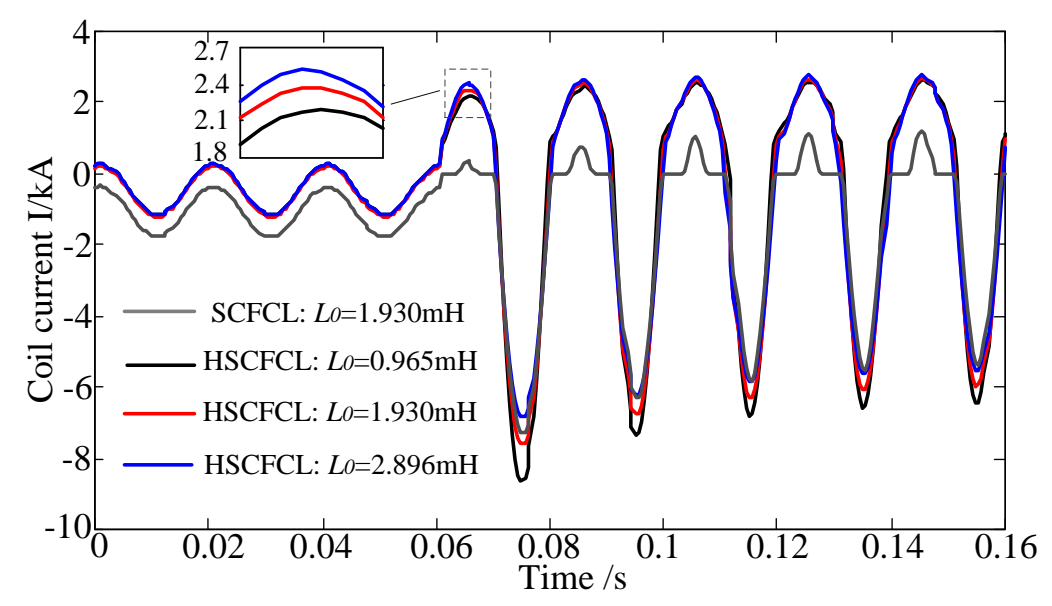

Figure 8. Currents of the coil on core II under different limiting inductances.

Figure 9 shows the flux density distribution of the HSCFCL under different conditions. Under normal conditions, cores I and II are both saturated, the flux density of cores I and II is about $2.05 \mathrm{~T}$, and the flux density of the PM is $1.12 \mathrm{~T}$. Under fault conditions, cores I and II are alternately driven out of saturation, respectively.

To validate the influence of a small-section structure on the saturation degree of the cores and biasing ability of the PMs, various comparative studies with different parameters of small sections are analyzed. The DC current is $1.0 \mathrm{kA}$.

Figure 10 shows the flux-density distribution of core I in different cross-sectional areas of the small section. It can be seen that, without the small section, due to the leakage effect the flux-density distribution of core I is uneven, the minimum B is $1.984 \mathrm{~T}$ in the center, and core I is not saturated. The use of the PM or the DC-biasing capacity should be increased to drop the cores into saturation. The length of the PM should be increased to $0.22 \mathrm{~m}$ for driving the cores into saturation. With the small 
section, saturation is deep and the biasing ability of the PMs is enhanced. When $S_{b}=0.1935 \mathrm{~m}^{2}$ and $S_{b}=0.1912 \mathrm{~m}^{2}$, the minimum B can be enhanced to $1.9969 \mathrm{~T}$ and $1.9984 \mathrm{~T}$, but core I is still unsaturated. When $S_{b}=0.189 \mathrm{~m}^{2}$, the minimum B is $2.0003 \mathrm{~T}$, and core I is saturated. However, when $S_{b}$ is reduced to $0.1867 \mathrm{~m}^{2}$, the flux density of the core center increases, but the flux density of the core end decreases to $1.9923 \mathrm{~T}$, resulting in a weakening of the saturation degree. Hence, with the reduction of cross-sectional area of the small section, the saturation degree of the cores does not always increase, and is relatively optimal in $S_{b}=0.189 \mathrm{~m}^{2}$.
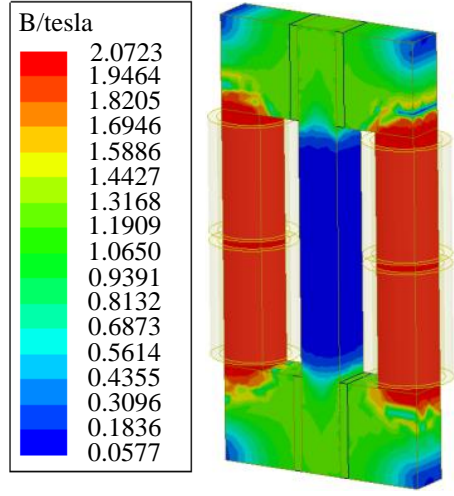

(a) Under normal conditions

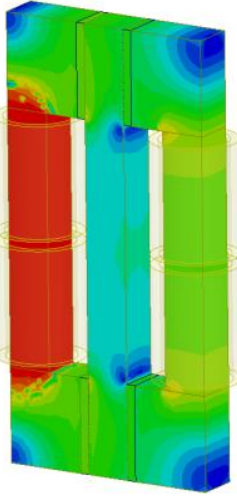

Positive cycle

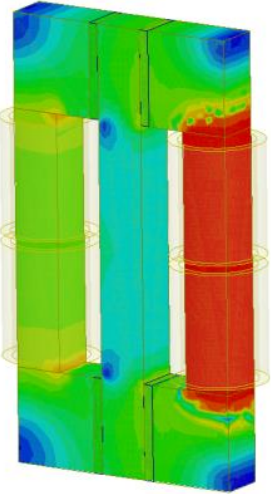

Negative cycle

(b) Under fault conditions

Figure 9. Flux density distribution of the HSCFCL under different conditions.

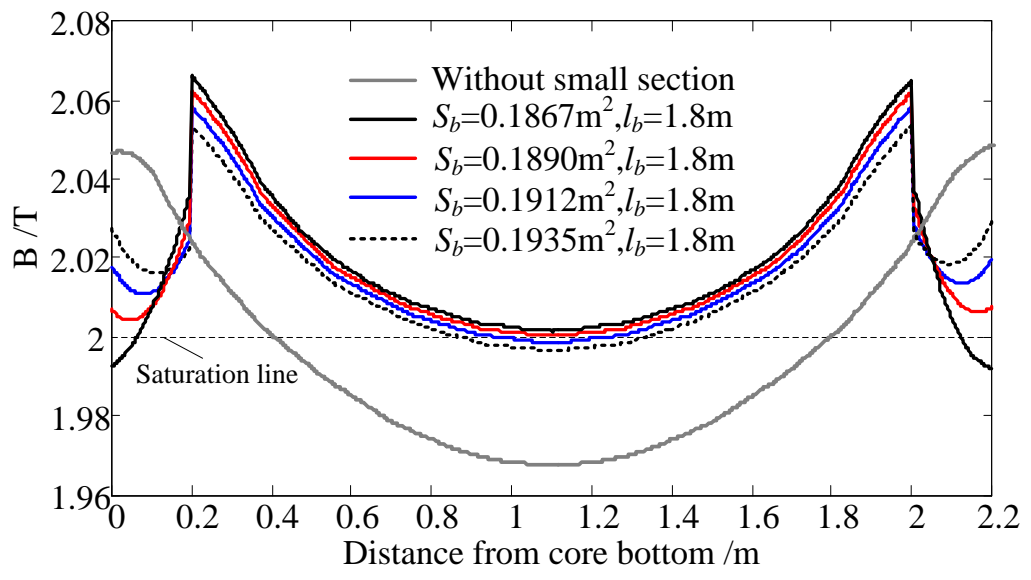

Figure 10. Flux-density distribution of core I in different cross-sectional areas of the small section.

Figure 11 shows the flux-density distribution of core I in different lengths of the small section. When $l_{b}=1.9 \mathrm{~m}$ and $l_{b}=2.0 \mathrm{~m}$, the flux density can be improved to $1.9982 \mathrm{~T}$ and $1.996 \mathrm{~T}$, but core I is still unsaturated. When $l_{b}=1.8 \mathrm{~m}$, core I is saturated with $2.0003 \mathrm{~T}$. However, when the length is reduced to $1.7 \mathrm{~m}$, the flux density near the junction of the small section and core I is reduced to $1.9868 \mathrm{~T}$. Hence, with the reduction in length of the small section, the saturation degree of cores does not always increase, and is relatively optimal at $l_{b}=1.8 \mathrm{~m}$.

This demonstrates that the small-section optimal structure can improve the saturation degree of cores, resulting in a reduction in the use of PMs and DC-biasing capacity. Moreover, the cross-sectional area and length of the small section have a significant influence on the improvement. The optimal parameter of the small section is $S_{b}=0.189 \mathrm{~m}^{2}, l_{b}=1.8 \mathrm{~m}$. The length of the PM for traditional hybrid SCFCLs without the small section should be increased to $0.22 \mathrm{~m}$ to drive the cores into saturation. Hence, compared with traditional hybrid SCFCLs without a small section, the length of the PM can be 
reduced from $220 \mathrm{~mm}$ to $150 \mathrm{~mm}$. The biasing ability of the PM can be improved by $31.8 \%$ with the optimal small-section structure.

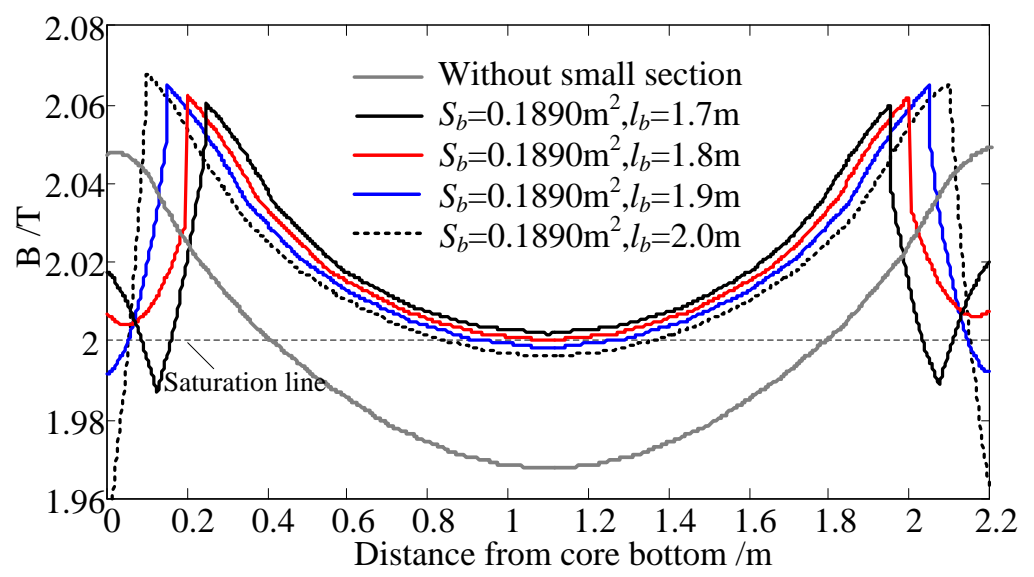

Figure 11. Flux-density distribution of core I in different lengths of the small section.

In addition, the energy consumption of the DC-biasing circuit under normal conditions has an important influence on the performance and cost of the HSCFCL. Reducing the energy consumption of the DC-biasing circuit under normal conditions can also improve the efficiency of the HSCFCL. As discussed previously, the DC-biasing current of SCFCLs without PMs is $2.0 \mathrm{kA}$, and the DC-biasing current of the HSCFCL can be reduced to $1.0 \mathrm{kA}$. Moreover, when the length of the PM is $150 \mathrm{~mm}$, the DC-biasing current of traditional hybrid SCFCLs will increase to $1.2 \mathrm{kA}$. Hence, assuming the lifetime of a FCL is 30 years $(263,000 \mathrm{~h})$, and each coil has a resistance of $0.05 \Omega$, the energy consumption can be calculated as:

SCFCLs without PMs: $W_{\text {loss } 1}=4 \times 2000^{2} \times 0.02 \times 263=84.16 \mathrm{GWh}$

Hybrid SCFCLs without small section: $W_{\text {loss } 2}=4 \times 1200^{2} \times 0.02 \times 263=30.30 \mathrm{GWh}$

HSCFCL with small section: $W_{\text {loss } 3}=4 \times 1000^{2} \times 0.02 \times 263=21.04 \mathrm{GWh}$

Hence, compared with SCFCLs without PMs, the proposed HSCFCL has a 75\% reduction of energy consumption under normal conditions. Compared with traditional hybrid SCFCLs without a small section, the proposed HSCFCL has a 30.5\% reduction of the energy consumption, resulting in an improvement in the efficiency of the HSCFCL under normal conditions.

The parameters of the PMs have an important impact on the improvement of the DC-biasing capacity. Moreover, since the reluctance of the PM will reduce the unsaturated inductance of the core, the parameters of PMs also have a significant impact on the limiting performance of the HSCFCL. Hence, to validate the influence of the PM on the performance of the HSCFCL, various comparative studies with different parameters of PMs are performed. The DC current is $1.0 \mathrm{kA}$, the parameter of the small section is $S_{b}=0.189 \mathrm{~m}^{2}$, and $l_{b}=1.8 \mathrm{~m}$.

Figure 12 shows the flux-density distribution of core I in different lengths of PMs. When the length of the PM is $0.13 \mathrm{~m}, 0.15 \mathrm{~m}$ and $0.17 \mathrm{~m}$, the minimum flux density is $1.9977 \mathrm{~T}, 2.0003 \mathrm{~T}$ and $2.0036 \mathrm{~T}$, respectively. Thus, as the length of the PM increases, the saturation degree also increases.

Figure 13 shows the limiting performance in different lengths of PM. When the lengths of the PM are $0.13 \mathrm{~m}, 0.15 \mathrm{~m}$ and $0.17 \mathrm{~m}$, the peak fault current can be limited to $10.77 \mathrm{kA}, 11.00 \mathrm{kA}$ and $11.34 \mathrm{kA}$, respectively. If the length of the PM increases, unsaturated inductance will decrease, and the length of the PM has a significant influence on the limiting performance. Hence, increasing the length of the PM can improve the saturation degree and reduce the DC-biasing capacity but will increase the cost and weaken the limiting performance. 


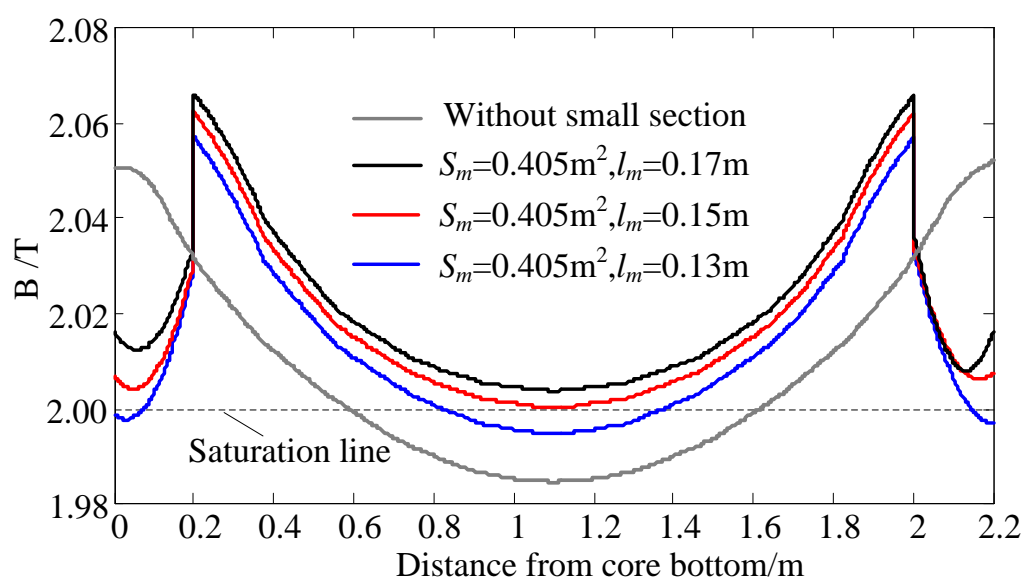

Figure 12. Flux density distribution of core I in different lengths of PMs.

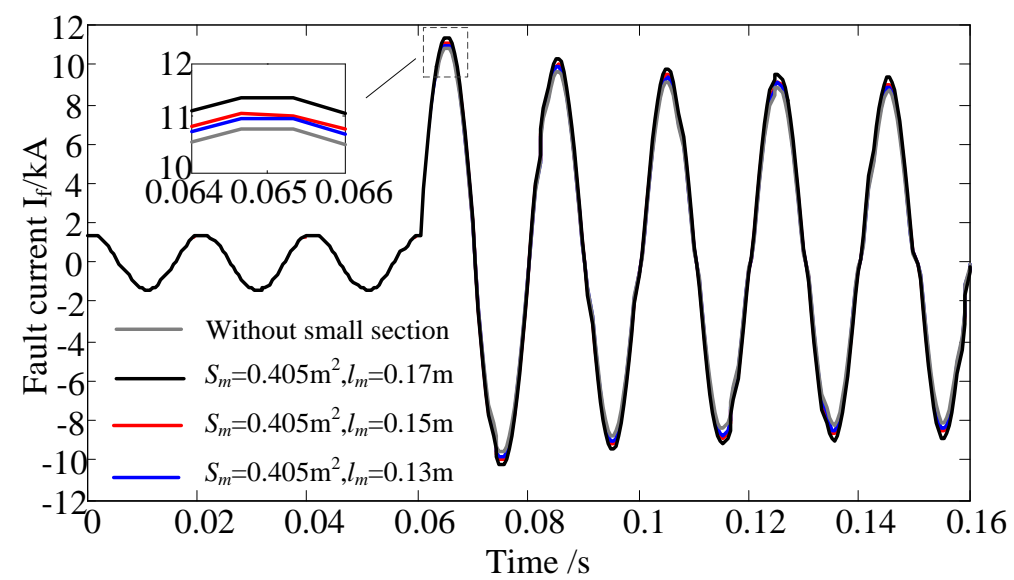

Figure 13. Limiting performance in different lengths of the PM.

Figures 14 and 15 show the flux-density distribution of cores and the limiting performance in different cross-sectional areas of the PM. It can be seen that as the cross-sectional area of PM increases, the saturation degree also increases effectively. When the cross-sectional area of the PM increases from $0.382 \mathrm{~m}^{2}$ to $0.427 \mathrm{~m}^{2}$, the minimum flux density also increases from $1.9959 \mathrm{~T}$ to $2.0029 \mathrm{~T}$. Moreover, the cross-sectional area of the PM has little impact on the limiting performance.

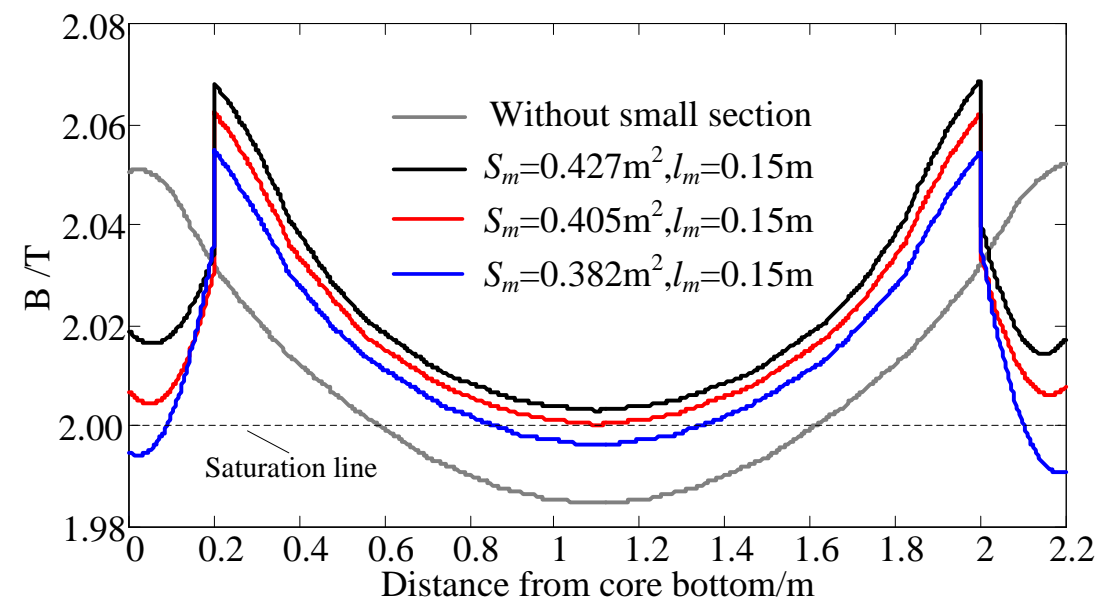

Figure 14. Flux-density distribution of cores in the different cross-sectional areas of the PM. 


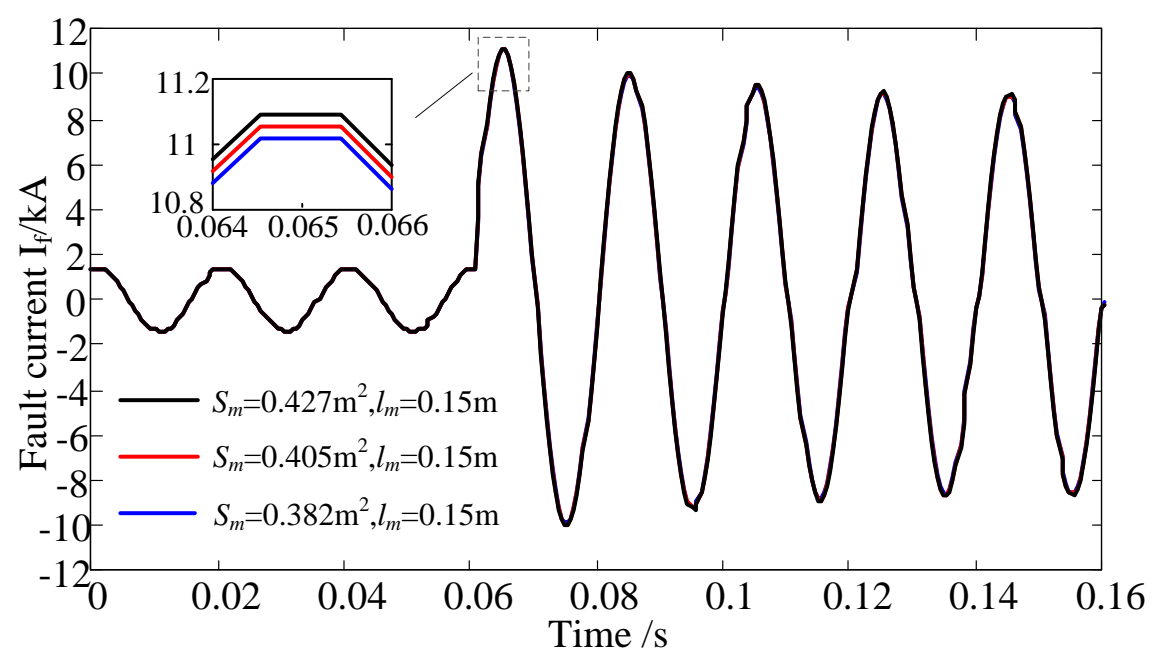

Figure 15. Limiting performance in the different cross-sectional areas of the PM.

Additionally, compared with Case 1: $S_{m}=0.405 \mathrm{~m}^{2}, l_{m}=0.15 \mathrm{~m}$, Case 2: $S_{m}=0.405 \mathrm{~m}^{2}, l_{m}=0.17 \mathrm{~m}$ can reduce the DC capacity of $0.1 \mathrm{kA}$, but will increase the usage of the PM of $0.0081 \mathrm{~m}^{3}$, and weaken the limiting performance of $0.34 \mathrm{kA}$. However, Case 3: $S_{m}=0.427 \mathrm{~m}^{2}, l_{m}=0.15 \mathrm{~m}$ can also reduce the DC capacity of $0.1 \mathrm{kA}$, but will just increase usage of the PM of $0.0031 \mathrm{~m}^{2}$, and has little impact on the limiting performance. Hence, compared with an increase in the length of the PM, an increase in the cross-sectional area of the PM has better performance and economy.

\subsection{Experimental Study}

To validate the performance and optimization studies of the HSCFCL proposed by this paper, a $220 \mathrm{~V} / 10$ A single-phase HSCFCL laboratory prototype was tested, as shown in Figure 16a. The parameters of the experimental prototype are shown in Table 3. The electrical circuit of the 220/10 A prototype test platform is shown in Figure 16b. The power supply was provided by a transformer. The prospective peak-fault current without FCL was $500 \mathrm{~A}$. The DC-biasing current was adjusted using a $100 \mathrm{~A}$ bridge rectifier. The exciting source was connected to the rectifier through an exciting transformer to ensure electrical insulation. A 400 A breaker was used to simulate a fault across the load. The currents were measured using 400 A AC/DC closed-loop Hall effect current sensors.

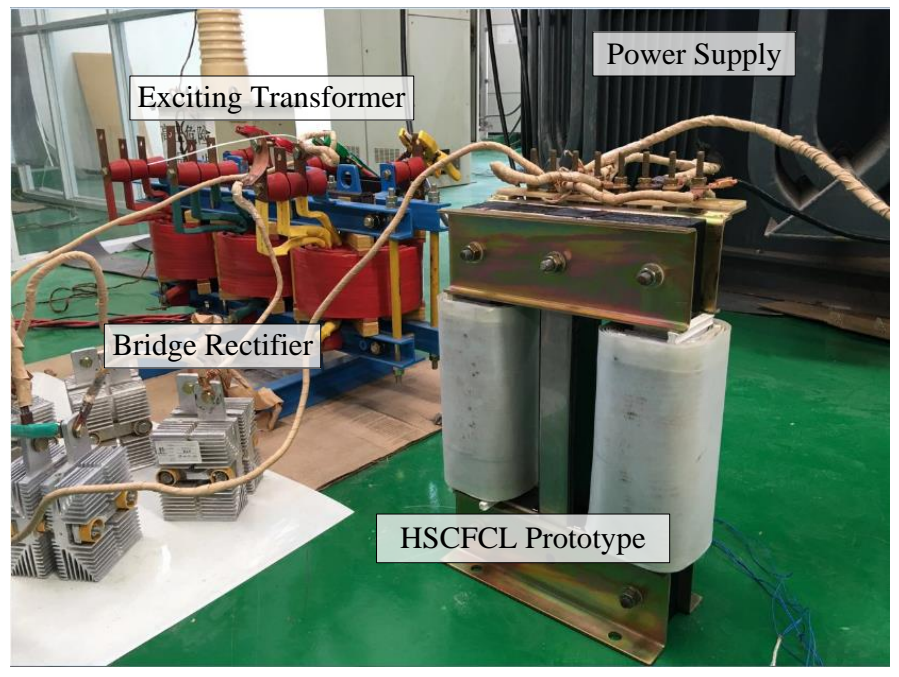

(a)

Figure 16. Cont. 


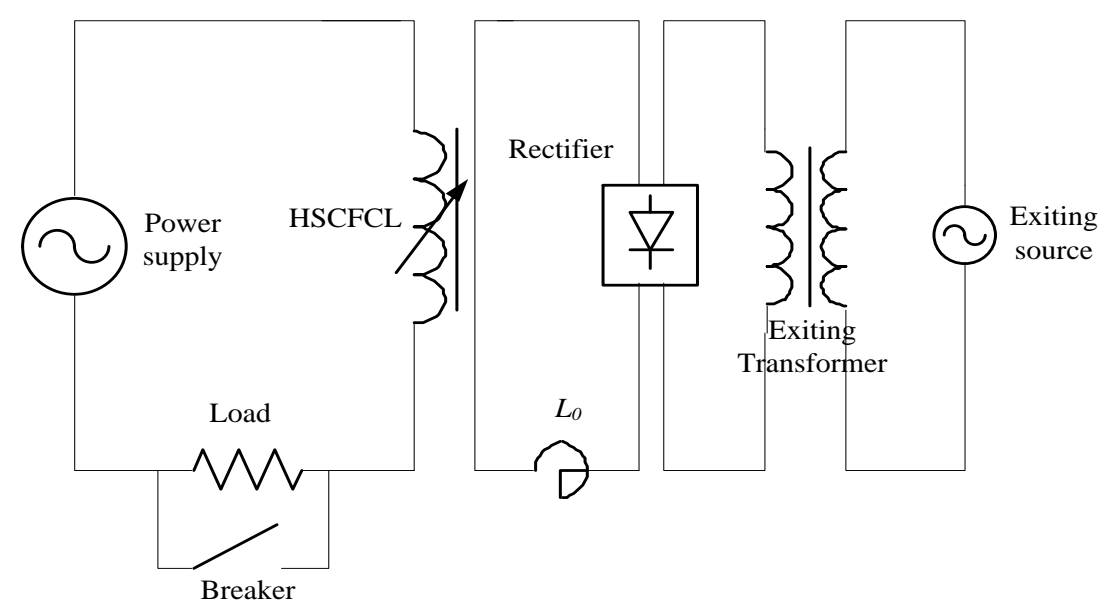

(b)

Figure 16. $220 \mathrm{~V} / 10$ A prototype test platform. (a) $220 \mathrm{~V} / 10 \mathrm{~A}$ HSCFCL prototype; (b) circuit scheme of the $220 \mathrm{~V} / 10$ A prototype test.

Table 3. Parameters of the $220 \mathrm{~V} / 10$ A HSCFCL laboratory prototype.

\begin{tabular}{cc}
\hline Parameter & Value \\
\hline Cross-sectional area of cores I and II $/ \mathrm{m}^{2}$ & 0.0025 \\
Cross-sectional area of cores III $/ \mathrm{m}^{2}$ & 0.00325 \\
Cross-sectional area of small section $/ \mathrm{m}^{2}$ & 0.00244 \\
Length of cores $l_{e} / \mathrm{m}$ & 0.27 \\
Length of small section $l_{b} / \mathrm{m}$ & 0.19 \\
Cross-sectional area of PM $/ \mathrm{m}^{2}$ & 0.005 \\
Length of PM $/ \mathrm{m}$ & 0.01 \\
DC-biasing current $/ \mathrm{A}$ & 10 \\
Steel cores & 8 \\
Permanent magnets & $H_{s}=10 \mathrm{kA} / \mathrm{m}, B_{s}=2.0 \mathrm{~T}$ \\
& $H_{c}=836 \mathrm{kA} / \mathrm{m}, B_{r}=1.45 \mathrm{~T}$ \\
\hline
\end{tabular}

Figure 17 shows the experimental limiting performance of the HSCFCL. Under normal conditions, the current is $10 \mathrm{~A}$. When a fault occurs, the HSCFCL can limit the fault current effectively. Due to the influence of the aperiodic component of the fault current, the fault current has a transient decay process. The first peak fault current with the HSCFCL can be limited to about $120 \mathrm{~A}$. The fault current is limited to approximately $70 \mathrm{~A}$ when it reaches a steady state. Additionally, the DC-biasing current of the HSCFCL under normal conditions is $10 \mathrm{~A}$. However, the DC-biasing current is $20 \mathrm{~A}$ without PMs. Hence, the DC-biasing capacity can be reduced by $50 \%$.

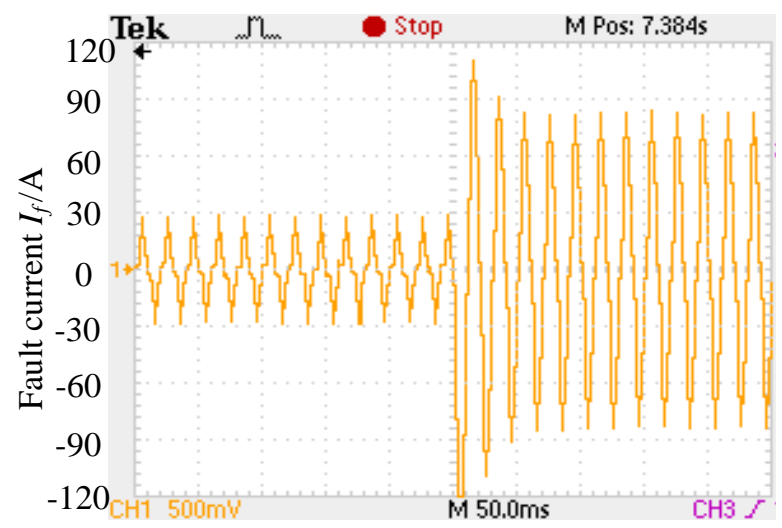

Figure 17. Experimental fault clipping performance of the HSCFCL. 
Figure 18 shows the fault current and DC-biasing current when the fault current reaches the steady state. It can be seen that the frequency of the DC-biasing current is $100 \mathrm{HZ}$. Due to the reluctance of the PM, the fault current will not only flow through the DC-biasing circuit, but also the windings in the unsaturated core. The DC-biasing current is a little smaller than the fault current. Hence, the experimental results validate the effectiveness of the proposed structure.

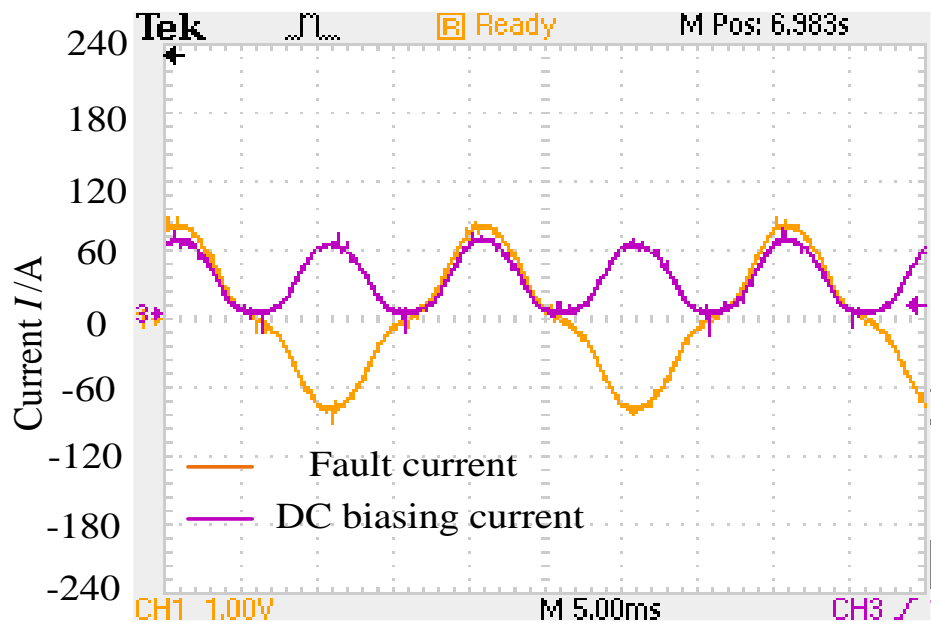

Figure 18. Fault current and DC-biasing current when the fault current reaches a steady state.

\section{Conclusions}

This paper presents a novel hybrid saturated-core fault-current limiter (HSCFCL), which has the advantages of small size, low DC-biasing capacity, high biasing ability of the PM, and excellent limiting performance. Compared with traditional SCFCLs, the DC-biasing capacity can be reduced by $50 \%$ and the biasing ability of the PM can be improved by $31.8 \%$ with optimal small-section structure.

The hybrid DC coil/PM structure is proposed for reducing the DC-biasing capacity. As the $M M F_{P M}$ increases, the improvement of the DC MMF will increase. Considering the limiting performance, the improvement of the DC MMF has a maximum value. In addition, according to the biasing ability of the PM when considering the leakage effect, the leakage effect will weaken the biasing ability of the PM, and the flux-density distribution of the cores is also uneven, resulting in an increase in the usage of the PM and DC-biasing capacity.

The small-section optimal structure can improve the biasing ability of the PM. The cross-sectional area and length of the small section have a significant influence on the level of improvement. Additionally, the cross-sectional area and length of the PM also have an important influence on the improvement of DC-biasing capacity and limiting performance. Compared with an increase in the length of the PM, an increase in the cross-sectional area of the PM can yield better performance and economy.

Acknowledgments: This work was supported in part by the National Natural Science Foundation of China under Grant No. 50807041.

Author Contributions: This article has seven authors: Liangliang Wei, Baichao Chen and Jiaxin Yuan conceived and designed the research method; Liangliang Wei, Cuihua Tian, Jiaxin Yuan and Yushun Liu performed the experiments; Liangliang Wei, Yuxin Bu and Tianan Zhu analyzed the data; and Liangliang Wei wrote the paper.

Conflicts of Interest: The authors declare no conflict of interest.

\section{References}

1. Kies, A.; Schyska, B.U.; von Bremen, L. Curtailment in a highly renewable power system and its effect on capacity factors. Energies 2016, 9, 510. [CrossRef] 
2. Sun, X.; Zhang, B.; Tang, X.; McLellan, B.C.; Höök, M. Sustainable Energy Transitions in China: Renewable Options and Impacts on the Electricity System. Energies 2016, 9, 980. [CrossRef]

3. Lu, J.; Wang, W.; Zhang, Y.; Cheng, S. Multi-Objective Optimization of Hybrid Renewable Energy System Using an Enhanced Multi-Objective Evolutionary Algorithm. Energies 2017, 10, 674. [CrossRef]

4. Abramovitz, A.; Smedley, K.M.; De La Rosa, F.; Moriconi, F. Prototyping and Testing of a 15 kV/1.2 kA Saturable Core HTS Fault Current Limiter. IEEE Trans. Power Deliv. 2013, 28, 1271. [CrossRef]

5. Radmanesh, H.; Fathi, S.H.; Gharehpetian, G.B.; Heidary, A. Bridge-Type Solid-State Fault Current Limiter Based on AC/DC Reactor. IEEE Trans. Power Deliv. 2016, 31, 200. [CrossRef]

6. Hong, H.; Su, B.; Niu, G.J.; Tian, B.; Li, Q.; Wang, L.Z.; Xin, Y.; Su, B.; Zhang, Z.H.; Zhang, K. Design, Fabrication, and Operation of the Cryogenic System for a $220 \mathrm{kV} / 300$ MVA Saturated Iron-Core Superconducting Fault Current Limiter. IEEE Trans. Appl. Supercond. 2014, 24, 1. [CrossRef]

7. Chen, L.; Chen, H.; Yang, J.; Yu, Y.; Zhen, K.; Liu, Y.; Ren, L. Coordinated Control of Superconducting Fault Current Limiter and Superconducting Magnetic Energy Storage for Transient Performance Enhancement of Grid-Connected Photovoltaic Generation System. Energies 2017, 10, 56. [CrossRef]

8. Xue, S.; Gao, F.; Sun, W.; Li, B. Protection Principle for a DC distribution system with a resistive superconductive fault current limiter. Energies 2015, 8, 4839-4852. [CrossRef]

9. Gunawardana, S.M.; Commins, P.A.; Moscrop, J.W.; Perera, W. Transient Modeling of Saturated Core Fault Current Limiters. IEEE Trans. Power Deliv. 2016, 31, 2008-2017. [CrossRef]

10. Commins, P.A.; Moscrop, J.W. Analytical Nonlinear Reluctance Model of a Single-Phase Saturated Core Fault Current Limiter. IEEE Trans. Power Deliv. 2013, 28, 450. [CrossRef]

11. Jia, Y.; Ainslie, M.D.; Hu, D.; Yuan, J. Numerical Simulation and Analysis of a Saturated-Core-Type Superconducting Fault Current Limiter. IEEE Trans. Appl. Supercond. 2017, 27, 1-5. [CrossRef]

12. Prigmore, J.R.; Mendoza, J.A.; Karady, G.G. Comparison of Four Different Types of Ferromagnetic Materials for Fault Current Limiter Applications. IEEE Trans. Power Deliv. 2013, 28. [CrossRef]

13. Jia, Y.; Shi, Z.; Zhu, H.; Geng, Y.; Zou, J.; Yuan, J. Cognition on the Current-Limiting Effect of Saturated-Core Superconducting Fault Current Limiter. IEEE Trans. Magn. 2015, 51, 1-4. [CrossRef]

14. Oliveira, F.; Amorim, A.; Encarnação, L.; Fardin, J.; Orlando, M.; Silva, S.; Simonetti, D. Enhancing LVRT of DFIG by using a superconducting current limiter on rotor circuit. Energies 2016, 9, 16. [CrossRef]

15. Chen, L.; Tu, X.; Chen, H.; Yang, J.; Wu, Y.; Shu, X.; Ren, L. Technical Evaluation of Superconducting Fault Current Limiters Used in a Micro-Grid by Considering the Fault Characteristics of Distributed Generation, Energy Storage and Power Loads. Energies 2016, 9, 769. [CrossRef]

16. Mukhopadhyay, S.C.; Dawson, F.P.; Iwahara, M.; Yamada, S. A novel compact magnetic current limiter for three phase applications. IEEE Trans. Magn. 2000, 36, 3568. [CrossRef]

17. Knott, J.C.; Moscrop, J.W. Increasing Energy Efficiency of Saturated-Core Fault Current Limiters with Permanent Magnets. IEEE Trans. Magn. 2013, 49, 4132. [CrossRef]

18. Yuan, J.; Lei, Y.; Wei, L.; Tian, C.; Chen, B.; Du, Z. A novel bridge-type hybrid saturated core fault current limiter based on permanent magnets. IEEE Trans. Magn. 2015, 51, 1-4. [CrossRef]

19. Li, Q.; Xu, J.; Zou, L.; Lou, J. Modelling methodology and experimental verification of the permanent-magnet-biased saturation-based fault current limiter. IET Electr. Power Appl. 2012, 6, 504. [CrossRef]

20. Wei, L.; Chen, B.; Yuan, J.; Tian, C.; Zhong, Y.; Li, X.; Gao, Y.; Muramatsu, K. Performance and Optimization Study of a Novel Compact Permanent-magnet-biased Fault Current Limiter. IEEE Trans. Magn. 2017, 53, 1-4. [CrossRef]

21. Moscrop, J.W. Experimental Analysis of the Magnetic Flux Characteristics of Saturated Core Fault Current Limiters. IEEE Trans. Magn. 2012, 49, 874. [CrossRef]

22. Chen, B.; Wei, L.; Tian, C.; Lei, Y.; Yuan, J. Parameter Design and Performance Investigation of A Novel Bridge-Type Saturated Core Fault Current Limiter. IEEE Trans. Power Deliv. 2017, 32, 1049. [CrossRef]

(C) 2018 by the authors. Licensee MDPI, Basel, Switzerland. This article is an open access article distributed under the terms and conditions of the Creative Commons Attribution (CC BY) license (http:/ / creativecommons.org/licenses/by/4.0/). 